\title{
Partial dentures by centrifugal casting assisted by additive manufacturing
}

\author{
GURPARTAP SINGH ${ }^{1}$, RUPINDER SINGH ${ }^{2, *}$ (D and SARBJIT SINGH ${ }^{1}$ \\ ${ }^{1}$ Department of Industrial and Production Engineering, Dr B R Ambedkar, National Institute of Technology, \\ Jalandhar 144011, India \\ ${ }^{2}$ Department of Production Engineering, Guru Nanak Dev Engineering College, Ludhiana 141006, India \\ e-mail: gurpartapbanny@gmail.com; rupindersingh78@yahoo.com; balss@ nitj.ac.in
}

MS received 23 October 2018; revised 26 February 2019; accepted 18 March 2019; published online 14 May 2019

\begin{abstract}
This research work focuses on preparation of partial dentures (as functional prototypes) by additive manufacturing (AM)-assisted centrifugal casting (CC). The master pattern for partial dentures was prepared on fused deposition modelling (FDM) set-up (established by AM technique at low cost). The final dentures as functional prototypes were prepared with a nickel-chromium (Ni-Cr)-based alloy by varying different proportions of $\mathrm{Ni} \%(N)$ by weight $\%$. The other input parameters were powder to water $P / W$ ratio $(W)$ and $\mathrm{pH}$ value $(H)$ of water used for mixing the investment. The samples prepared were ascertained for dimensional deviation $(\Delta d)$, surface finish $\left(R_{\mathrm{a}}\right)$ and micro-hardness $(\mathrm{HV})$ as output parameters. Finally, multifactor optimization has been applied on output parameters of functional prototypes prepared. This study highlights that partial denture prepared with $\mathrm{W}-100 / 15, \mathrm{H}-7$ and $\mathrm{N}-61 \%$ gives overall better results from mechanical properties and dimensional accuracy viewpoint. The results are also supported by photo-micrographic analysis.
\end{abstract}

Keywords. Partial denture; additive manufacturing; $\mathrm{pH}$ value; $\mathrm{P} / \mathrm{W}$ ratio; $\mathrm{Ni}-\mathrm{Cr}$ alloy.

\section{Introduction}

The commercially prepared partial dentures are removable or of fixed type depending on patient health, age, glucose level, etc. [1]. Dentures may have clasps and metal frameworks designed to hold the denture in the oral cavity as artificial replacement [2]. In spite of the fact that clinician's ability and experience play a noteworthy part in forming and creation of partial denture [3], clinician's final judgment still prevails on the exactness of the final denture prepared [4]. Also, the fabrication of partial dentures and metal frameworks includes manual procedure that requires skill and experience and may take quite a while to finish [5-7]. However, sometimes partial dentures provide less power of chewing as that of natural teeth and may be risky and irritating [8]. Computer-aided design/computer-aided manufacturing (CAD/CAM) advancements in the dentistry may help overcome issues of manual work $[9,10]$. Reverse engineering (RE) under CAD/CAM involves the process of creating a three-dimensional (3D) CAD component by capturing the surface outline shapes of physical component for designing by extricating the design sequence of current part and the process sequence of manufacturing and design is re-engineered [11-14]. Earlier, digital casts depended upon subtractive methods, which were widely used for

*For correspondence construction of dental restorations and sacrificial patterns [15]. Delivering higher- and more-uniform-quality dentures/metal frameworks relied exclusively on CAD/CAM techniques and was used commercially for producing/standardizing dentures with low production and labour costs in less time [16]. Nowadays, additive manufacturing (AM) techniques have progressed vastly in dental applications with accurate and high-rate production [17, 18]. These techniques have the ability to overcome identified disadvantages such as fit problems caused by CAD/CAM techniques. Since 1990s, AM techniques were used in dentistry to construct complex shaped 3D models [19]. AM in dentistry is called as perfect fit and different applications have been successfully proposed due to the high reproducibility and quality. Some of the examples are maxillofacial implants, partial dentures, metal frameworks surgical guides, zirconia dentures, full denture and wax patterns for different prosthetic aids [20-22]. Latest studies using AM techniques allow digital dental 3D surveying prior to the fabrication of dentures and sacrificial pattern frameworks [23]. The AM techniques such as fused deposition modelling (FDM), vat polymerization, selective laser sintering (SLS), pro-jet printing, digital light projection (DLP), material jetting and fused filament deposition (FFF) are very commonly used in clinical dentistry. The AM approach has some advantages in dentistry such as elimination of inter-operator variation, repeatability, 
manufacturing time reduction and low cost [24-26]. The FDM process has capability for producing cost-effective tailor-made products at low cycle time that are best suited for dental applications [27, 28]. In the past some researchers have prepared denture samples using double distilled water and sea water with higher W/P ratio (than recommended by commercial manufacturers) that has significant effects on the setting time, hardness and compressive strength [29]. Similarly, dimensional accuracy by comparison of different die materials has good response by using AM technology $[30,31]$. Surface finish is also a considerable factor in the cast restoration margin evenness/ fineness $[32,33]$. In dentistry the dental casting alloys are classified mainly into high noble alloys (gold and platinum), noble alloys (silver, gold and copper) and base metal alloys (Ni-based, Co-based and Ti-based). For metal restoration and crown making, base metal alloys may be used [34, 35].

In clinical dentistry commercially, gold alloys (high noble alloys) have been used. However, Ni-Cr-based alloys replace the other alloys irrespective of their excellent properties due to less cost involved. Among other alloys, $\mathrm{Ni}-\mathrm{Cr}$ became popular also because of their capability of producing light and thin frameworks with excellent mechanical properties and satisfactory corrosion resistance [36-38]. Mechanical properties have some effect on Ni-Crbased alloy with respect to casting and melting procedures [39]. The published literature outlined that $W, H$ of water and weight proportion of $\mathrm{N}$ in Ni-Cr-based alloy are some of the main factors that affect the output properties of partial dentures made by AM and cast by centrifugal casting (CC). However, hitherto, very less work has been reported for fabrication of partial dentures by FDM (one of the AM techniques) and cast by $\mathrm{CC}$ from multifactor optimization viewpoint. The aim of this study is to ascertain the conditions for optimum values of $\Delta d, R_{\mathrm{a}}$ and HV. Further, multifactor optimization has been employed from field engineer viewpoint so that the finally prepared partial dentures can be commercially used without further required iterations.

\section{Methodology and experimentation}

In the present work, patient-specific biomedical component (dental crown) has been selected as the benchmark as shown in figure 1.

Starting from the benchmark as shown in figure 1, this study is formally divided into 12 steps/stages to prepare the final cast of partial dentures. The process of casting of partial denture begins with a dental impression of the patient's teeth (stage 1). This dental impression prepared was further used for formal diagnostic impression/cast. After obtaining appropriate dental impression/cast, gypsum, high-strength stone also known as artificial stone is used to make the final cast of teeth mould (stage 2). The dental investment (refractory material) is mixed (mixture of bonded investment and water) by taking three different $W$ by weight $(100 / 12,100 / 15,100 / 18)$ using different $\mathrm{H}$ of water (pH-3, pH-7, pH-10). An optical scanner (three-dimensional (3D) representation) collected the surface information (exact size and shape) of the plaster cast (teeth mould) of the patient in the form of digital data and were saved in 3D software, which were then used to shape the partial denture framework and pre-process the data with reference to the scanned digital model. The CAD model of the partial denture has been made, and then converted into a standard triangulation language (STL) file to build the partial denture of ABS (material) with FDM (stages 3-5). Thereafter, attachment of sprue and ring liner placement are done in the crucible before investing. After this, investment is poured slowly around the pattern tree in the crucible (stages 6-7). Burn-out and baking process of investment by placing in a muffle furnace for $1.5 \mathrm{~h}$ at $900^{\circ} \mathrm{C}$ was performed in subsequent stages (stages 8-9). A Ni-Cr-based alloy was used for castings of partial denture on the induction casting set-up (stages 10-11). After solidification, the final casting fitted on the denture mould was procured (stage 12, figure 2). Based on previous literature, a cause and effect diagram has been prepared for predicting best settings of input parameters (see figure 3). The levels selected for various parameters are shown in table 1.

The $\Delta d$ value of one critical dimension of $10.70 \mathrm{~mm}$ was selected as a benchmark (see figure 1). A Mitutoyo-SJ-410 roughness tester (as per ISO-1997 at $0.5 \mathrm{~mm} / \mathrm{s}$ stylus speed and $0.25 \mathrm{~mm}$ cut-off length) was used to measure the benchmark component values of $R_{\mathrm{a}}$, and $\Delta d$ was measured using a Mitutoyo Vernier calliper (accurate up to $0.01 \mathrm{~mm}$ ). The hardness of the cast has been measured using a microVickers (HV) hardness tester.

For preparation of denture through CC, parameters were selected and altered as per Taguchi L9 orthogonal array. After getting all the observations in the form of outputs from the mechanical testing, results were analysed for multifactor optimization and ANOVA analysis using MINITAB $\odot$ software. Table 2 shows the chemical composition of the Ni-Cr alloy for casting of partial dentures. Based upon table 1, table 3 shows the control $\log$ of experimentation based upon Taguchi L9 orthogonal array and the outputs $\Delta d, R_{\mathrm{a}}$ and $\mathrm{HV}$.

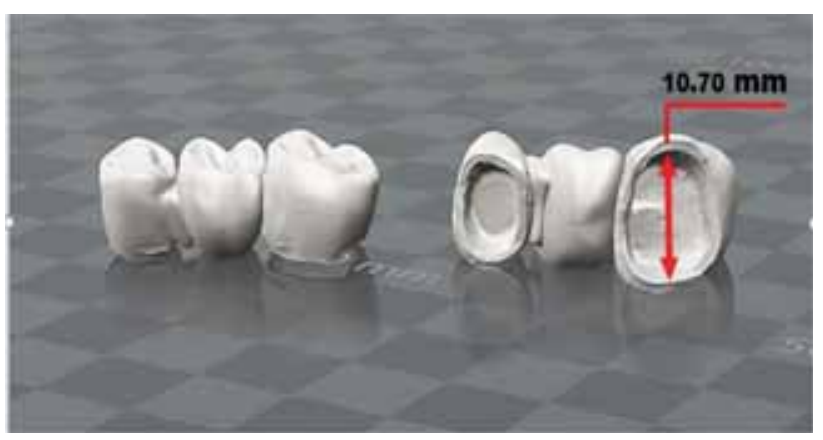

Figure 1. Benchmark component. 

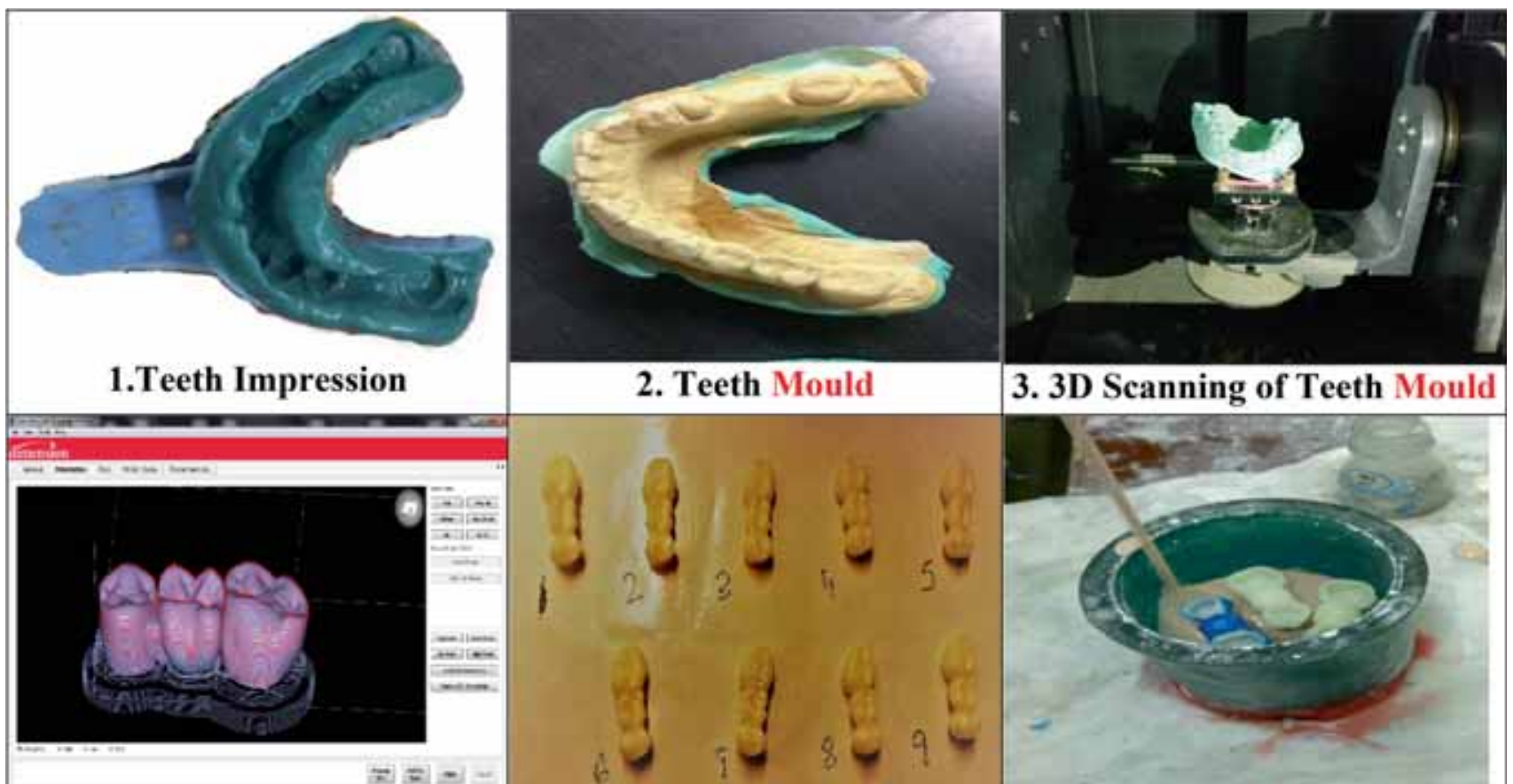

2. Teeth Mould

\section{3D Scanning of Teeth Mould}

$=1-1-$

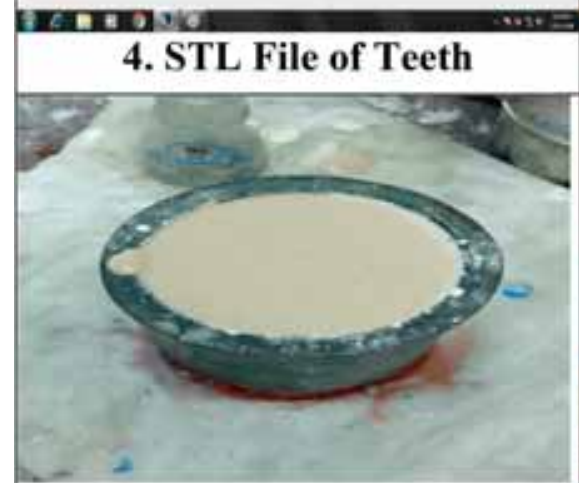

5

\section{ABS Patterns}

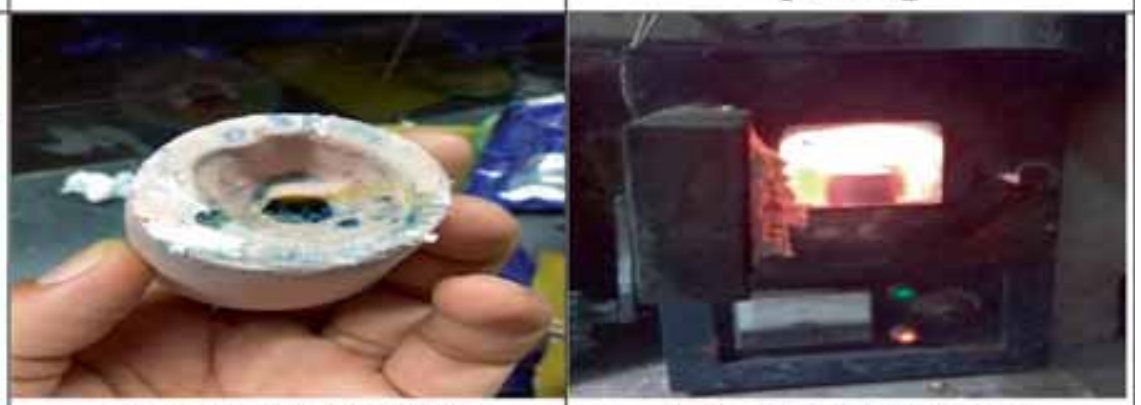

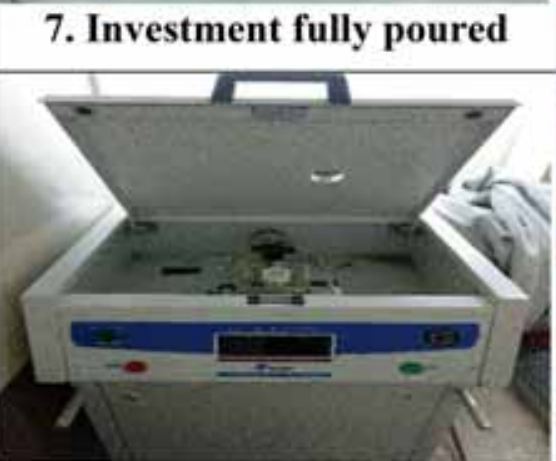

10. Induction Casting

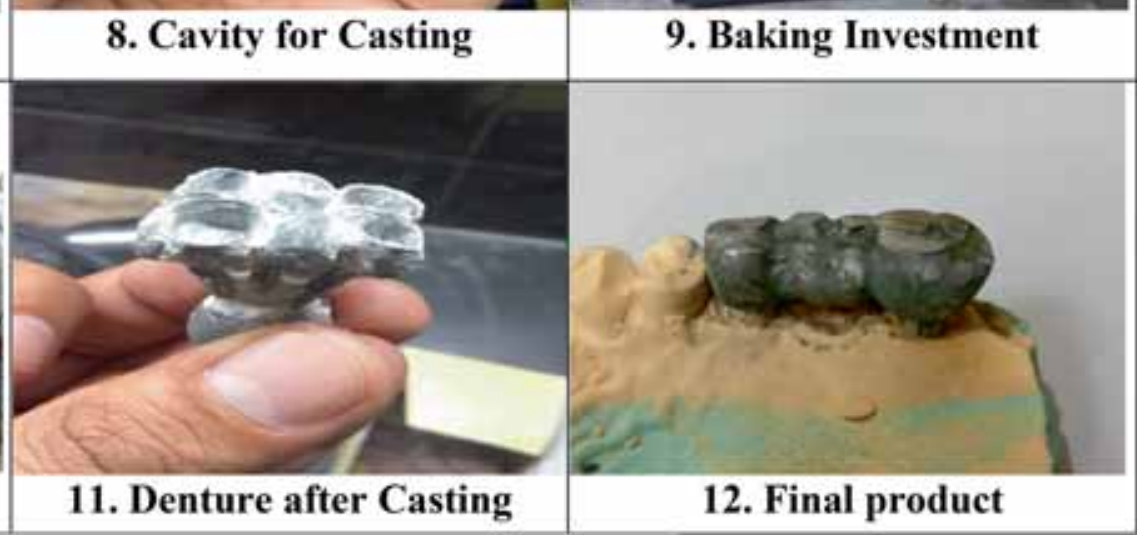

Figure 2. Steps involved in making partial denture.

\section{Results and discussion}

Further based upon table 3 , table 4 shows the signal to noise ratio of $\Delta d$ (SNRA1), $R_{\mathrm{a}}$ (SNRA2) and HV (SNRA3).

Based upon table 4 , figure 4 shows the main effects plot for mean $S / N$ ratios for $\Delta d, R_{\mathrm{a}}$ and $\mathrm{HV}$. As observed from figure 4 , for $\Delta d$, best settings are $W$ of $100 / 12$, pH-7 with $61 \%$ of $N$ in Ni-Cr alloy. Since $\Delta d, R_{\mathrm{a}}$ have been computed for lower the better type case, the $W$ of $100 / 12$ is but obvious as less proportion of water results in less contraction after solidification and hence less dimensional deviations and better surface finish. The $\mathrm{pH}$ of 7 provides a 


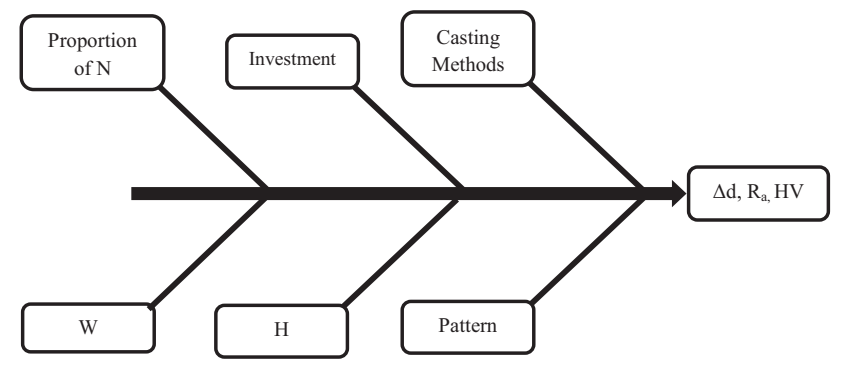

Figure 3. Cause and effect diagram.

Table 1. Input parameters and levels for experimentation.

\begin{tabular}{lcccc}
\hline & & \multicolumn{3}{c}{ Input parameters } \\
\cline { 3 - 5 } & & \multicolumn{3}{c}{ Levels } \\
\cline { 3 - 5 } Factor & Symbol & 1 & 2 & 3 \\
\hline$W$ & $A$ & $100 / 12$ & $100 / 15$ & $100 / 18$ \\
$H$ & $B$ & $\mathrm{pH}-3$ & $\mathrm{pH}-7$ & $\mathrm{pH}-10$ \\
$N$ & $C$ & $61 \%$ & $65 \%$ & $70 \%$ \\
\hline
\end{tabular}

Table 2. Ni-Cr alloy (\%) for casting of partial denture.

\begin{tabular}{lccc}
\hline & \multicolumn{3}{c}{ Ni-Cr alloy (wt\%) } \\
\cline { 2 - 4 } & 1 & 2 & 3 \\
\hline $\mathrm{Ni}$ & 61 & 65 & 70 \\
$\mathrm{Cr}$ & 25.60 & 22.50 & 13 \\
$\mathrm{Si}$ & 0.47 & 1 & 4 \\
$\mathrm{Co}$ & 0.31 & - & - \\
$\mathrm{Mn}$ & 0.03 & - & - \\
$\mathrm{Mo}$ & 11.06 & 9.50 & - \\
$\mathrm{Cu}$ & - & 1.6 & 13 \\
\hline
\end{tabular}

Table 3. Results of output parameters according to Taguchi L9 orthogonal array.

\begin{tabular}{lclcccc}
\hline Sl. & & & & & & $\begin{array}{c}\text { Micro- } \\
\text { no. }\end{array}$ \\
\hline 1 & $W$ & $H$ & $N(\%)$ & $\Delta d(\mathrm{~mm})$ & $\begin{array}{c}R_{\mathrm{a}} \\
(\mu \mathrm{m})\end{array}$ & $\begin{array}{c}\text { hardness } \\
(\mathrm{HV})\end{array}$ \\
2 & $100 / 12$ & $\mathrm{pH}-3$ & 61 & 0.05 & 9.620 & 169.03 \\
3 & $100 / 12$ & $\mathrm{pH}-7$ & 65 & 0.03 & 3.866 & 171.30 \\
4 & $100 / 12$ & $\mathrm{pH}-10$ & 70 & 0.08 & 8.241 & 159.63 \\
5 & $100 / 15$ & $\mathrm{pH}-3$ & 65 & 0.11 & 6.040 & 182.70 \\
6 & $100 / 15$ & $\mathrm{pH}-10$ & 61 & 0.10 & 4.047 & 197.97 \\
7 & $100 / 18$ & $\mathrm{pH}-3$ & 70 & 0.11 & 7.897 & 152.27 \\
8 & $100 / 18$ & $\mathrm{pH}-7$ & 61 & 0.06 & 9.422 & 174.30 \\
9 & $100 / 18$ & $\mathrm{pH}-10$ & 65 & 0.09 & 7.705 & 181.97 \\
\hline
\end{tabular}

Note: For $\Delta d, R_{\mathrm{a}}$ and $\mathrm{HV}$, three repetitions have been made and average of three values has been taken to reduce the experimental error.
Table 4. SNRA data of output parameters according to Taguchi L9 orthogonal array.

\begin{tabular}{lcccccc}
\hline S1. & & & & $\begin{array}{c}S / N \text { ratio } \\
\text { for }\end{array}$ & $\begin{array}{c}S / N \text { ratio } \\
\text { for } R_{\mathrm{a}} \\
(\mathrm{dB})\end{array}$ & $\begin{array}{c}S / N \text { ratio } \\
\text { for } \mathrm{HV} \\
(\mathrm{dB})\end{array}$ \\
\hline no. & $W$ & $H$ & $N(\%)$ & $\Delta d(\mathrm{~dB})$ & & \\
\hline 1 & $100 / 12$ & $\mathrm{pH}-3$ & 61 & 26.0206 & -19.6635 & 44.5594 \\
2 & $100 / 12$ & $\mathrm{pH}-7$ & 65 & 29.5424 & -11.7452 & 44.6751 \\
3 & $100 / 12$ & $\mathrm{pH}-10$ & 70 & 22.3079 & -18.3196 & 44.0625 \\
4 & $100 / 15$ & $\mathrm{pH}-3$ & 65 & 19.1721 & -15.6207 & 45.2348 \\
5 & $100 / 15$ & $\mathrm{pH}-7$ & 70 & 22.6940 & -11.5245 & 44.1957 \\
6 & $100 / 15$ & $\mathrm{pH}-10$ & 61 & 19.7152 & -12.1427 & 45.9318 \\
7 & $100 / 18$ & $\mathrm{pH}-3$ & 70 & 19.4394 & -17.9492 & 43.6521 \\
8 & $100 / 18$ & $\mathrm{pH}-7$ & 61 & 24.9334 & -19.4829 & 44.8259 \\
9 & $100 / 18$ & $\mathrm{pH}-10$ & 65 & 20.5993 & -17.7355 & 45.1998 \\
\hline
\end{tabular}

neutral binding agent and the least proportion of $\mathrm{N}$ in $\mathrm{Ni}-\mathrm{Cr}$ alloy results in better dimensional as well as surface roughness, which may be because of more grain refinement (the same may be ascertained from photomicrographs). For $R_{\mathrm{a}}$, the best settings are $W 100 / 15$, pH-7 with $65 \%$ of $N$. For HV the best settings are $W 100 / 15, \mathrm{pH}-10$ with $61 \%$ of $N$.

Tables 5 and 6, respectively, show the ranking of input parameters (based upon responses of $S / N$ ratios) and percentage contributions for $\Delta d, R_{\mathrm{a}}$ and $\mathrm{HV}$.

As observed from table $6, W$ has the maximum contribution for $\Delta d$ and $R_{\mathrm{a}}$, whereas for HV the maximum contribution is $N$. These results are at $95 \%$ confidence level.

Further response optimization for all the three $S / N$ ratios given in table 3 has been performed using Minitab software (see table 7). For maximization of all the $S / N$ ratios, equal weight and importance has been given. The fit for the same has been calculated in table 8 . As observed from table 8 , the composite desirability for the proposed model is 0.698139, which gives promising outcomes to the best settings for all responses as a whole.

Based upon multi-regression analysis, multi-response predictor has given an optimized setting for the best results (see table 9).

The predicted setting is $2,2,1$, which could be demonstrated as the $2^{\text {nd }}$ level of $W$, i.e., $(100 / 15), 2^{\text {nd }}$ level of $H$ of water, i.e., $\mathrm{pH}-7$ and $1^{\text {st }}$ level of $N$, i.e., $61 \%$. The values obtained at this level are supposed to be the best values. Finally, after regression analysis based on outputs of $S / N$ ratio a linear model (regression equation) has been suggested.

\subsection{Regression equation}

\section{1a Regression equation for $S N$ ratio of $\Delta d$ :}

$$
\begin{aligned}
\text { SNRA1 }= & 22.714+3.243 W \_100 / 12-2.187 W \_100 / 15 \\
& -1.056 W \_100 / 18-1.170 H \_3+3.009 H \_7 \\
& -1.840 H \text { value } 10+0.843 N \_61+0.391 N \_65 \\
& -1.233 N \_70 .
\end{aligned}
$$




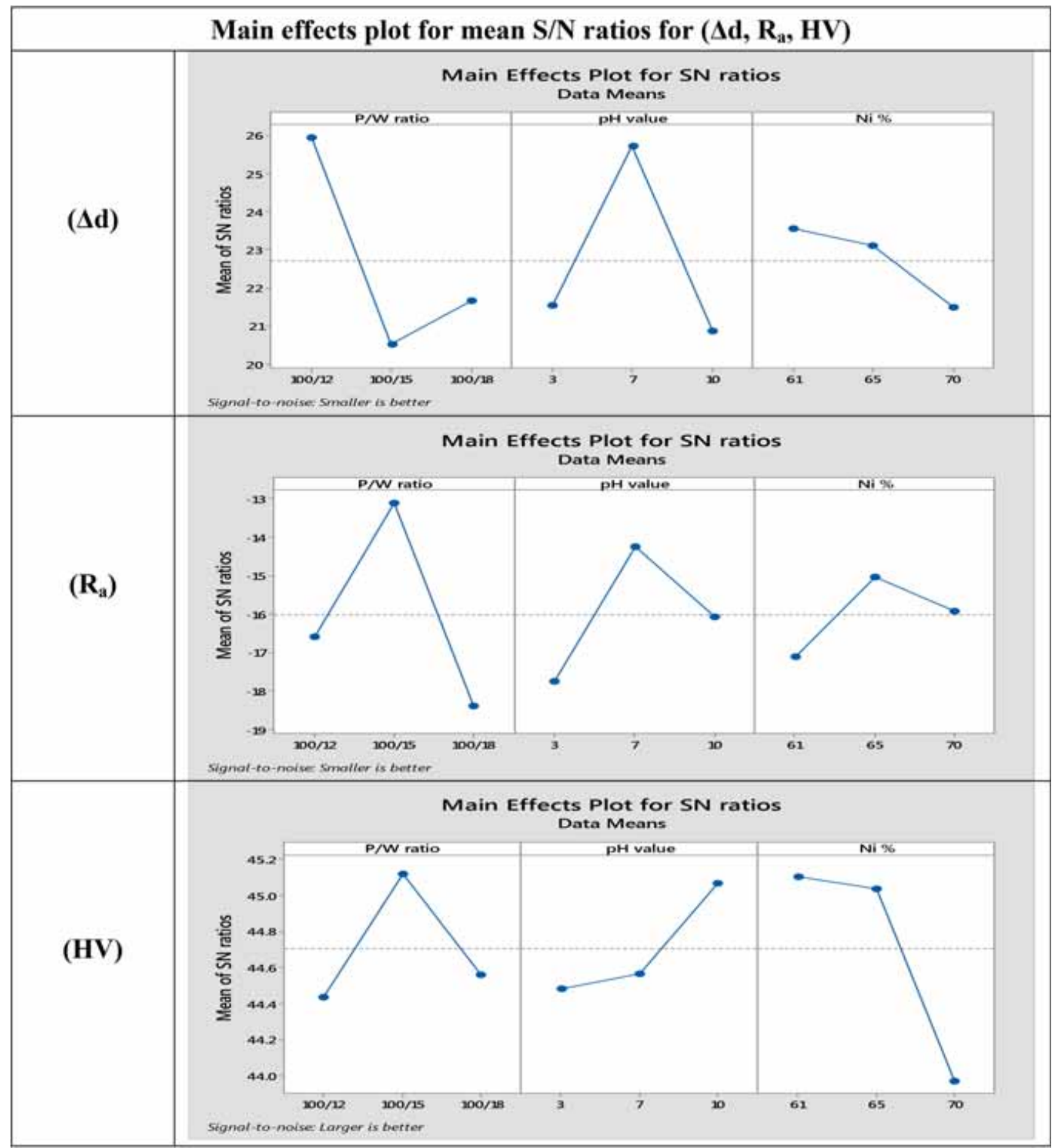

Figure 4. Main effects plot for mean $S / N$ ratios for $\left(\Delta d, R_{\mathrm{a}}, \mathrm{HV}\right)$. Note: $\Delta d, R_{\mathrm{a}}$ have been computed for lower the better type case and $\mathrm{HV}$ for higher the better type case.

Here $W 100 / 12, W \_100 / 15, W \_100 / 18, H \_3, H \_7, H \_10$, $N \_61, N \_65$ and $N \_70$ have been taken from table 4 . After putting the values form table 4 in Eq. (1), final maximized value has been obtained.

$$
\begin{aligned}
& \text { SNRA } 1=22.714+(3.243 \times 25.96)-(2.187 \times 20.53) \\
& \quad-(1.056 \times 21.66)-(1.170 \times 21.54)+(3.009 \times 25.72) \\
& \quad-(1.840 \times 20.87)+(0.843 \times 23.56)+(0.391 \times 23.10) \\
& \quad-(1.233 \times 21.48), \\
& \text { SNRA1 }=55.32743 \text { (predicted value }) .
\end{aligned}
$$


Table 5. Response of $S / N$ ratios for output parameters.

\begin{tabular}{|c|c|c|c|c|c|c|c|c|c|}
\hline \multirow[b]{2}{*}{ Level } & \multicolumn{3}{|c|}{$\Delta d(\mathrm{~mm})$} & \multicolumn{3}{|c|}{$R_{\mathrm{a}}(\mu \mathrm{m})$} & \multicolumn{3}{|c|}{ Microhardness (HV) } \\
\hline & $W$ & $H$ & $N$ & $W$ & $H$ & $N$ & $W$ & $H$ & $N$ \\
\hline 1 & 25.96 & 21.54 & 23.56 & -16.58 & -17.74 & -17.10 & 44.43 & 44.48 & 45.11 \\
\hline 2 & 20.53 & 25.72 & 23.10 & -13.10 & -14.25 & -15.03 & 45.12 & 44.57 & 45.04 \\
\hline 3 & 21.66 & 20.87 & 21.48 & -18.39 & -16.07 & -15.93 & 44.56 & 45.06 & 43.97 \\
\hline Delta & 5.43 & 4.85 & 2.08 & 5.29 & 3.49 & 2.06 & 0.69 & 0.58 & 1.14 \\
\hline Rank & 1 & 2 & 3 & 1 & 2 & 3 & 2 & 3 & 1 \\
\hline
\end{tabular}

Table 6. Percentage contribution for various responses.

\begin{tabular}{|c|c|c|c|c|c|c|}
\hline \multirow[b]{2}{*}{ Source } & \multicolumn{2}{|c|}{$\Delta d(\mathrm{~mm})$} & \multicolumn{2}{|c|}{$R_{\mathrm{a}}(\mu \mathrm{m})$} & \multicolumn{2}{|c|}{ Microhardness (HV) } \\
\hline & $P$-value & Contribution $(\%)$ & $P$-value & Contribution (\%) & $P$-value & Contribution (\%) \\
\hline$W$ & 0.031 & 49.55 & 0.344 & 47.76 & 0.019 & 20.92 \\
\hline$H$ & 0.036 & 41.68 & 0.554 & 20.15 & 0.025 & 15.47 \\
\hline$N$ & 0.179 & 7.19 & 0.780 & 7.06 & 0.006 & 63.19 \\
\hline Error & & 1.556 & & 22.744 & & 0.01548 \\
\hline
\end{tabular}

Table 7. Response optimization: SNRA3, SNRA 2 and SNRA1.

\begin{tabular}{|c|c|c|c|c|c|}
\hline Response & Goal & Lower & Target & Upper weight & Importance \\
\hline SNRA3(HV) & Maximum & 43.6521 & 45.9318 & 1 & 1 \\
\hline $\operatorname{SNRA} 2\left(R_{\mathrm{a}}\right)$ & Maximum & -19.6635 & -11.5245 & 1 & 1 \\
\hline $\operatorname{SNRA} 1(\Delta d)$ & Maximum & 19.1721 & 29.5424 & 1 & 1 \\
\hline
\end{tabular}

Table 8. Best setting obtained with best signal to noise ratios.

\begin{tabular}{lccccccc}
\hline Solution & $W$ & $H$ & $N$ & SNRA3 fit & SNRA2 fit & SNRA1 fit & Composite desirability \\
\hline 1 & $100 / 15$ & $\mathrm{pH}-7$ & 61 & 45.3838 & -12.4023 & 24.3792 & 0.698139 \\
\hline
\end{tabular}

Similarly, for $\mathrm{SN}$ ratio of $\Delta d$, final minimum value of the property has been predicted with the help of the following relations:

Following Eq. (2) and putting values in it from table 4 $\mathrm{SN}$ ratio $=-10 \log X$ (standard equation for finding $\mathrm{SN}$ ratio)

$$
\begin{aligned}
& 55.32743=-10 \log X \\
& X=10^{-5.532743} \\
& X=2.93263 \times 10^{-6} .
\end{aligned}
$$

Now put the value of $X$ in the next equation:

Table 9. Optimum values proposed by the software for castings.

\begin{tabular}{lccc}
\hline Variable & $W$ & $H$ & $N$ \\
\hline Setting & $100 / 15$ & $\mathrm{pH}-7$ & $61 \%$
\end{tabular}

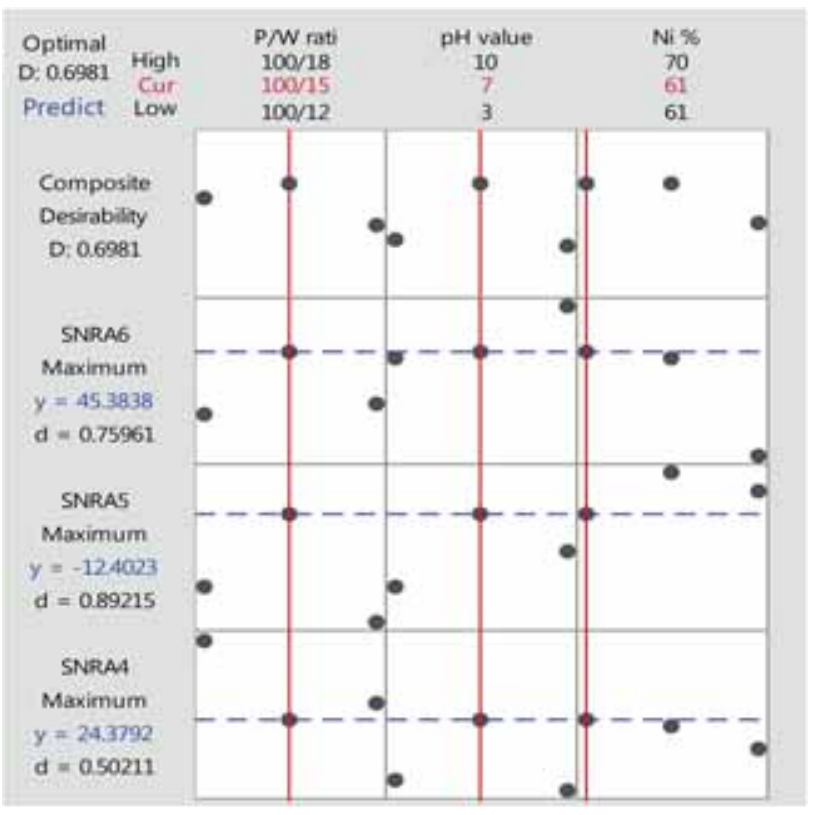

Figure 5. Optimization plot. 


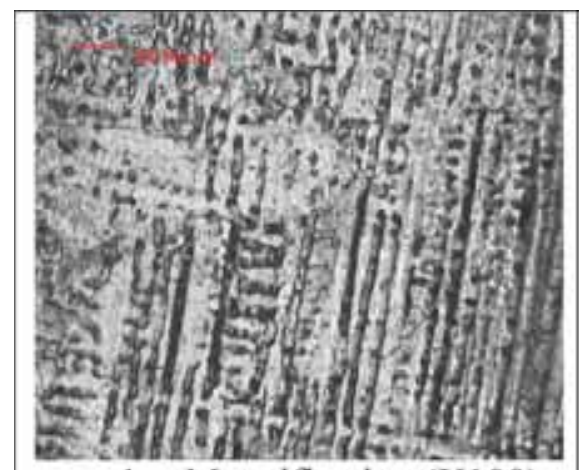

1. Magnification (X100)

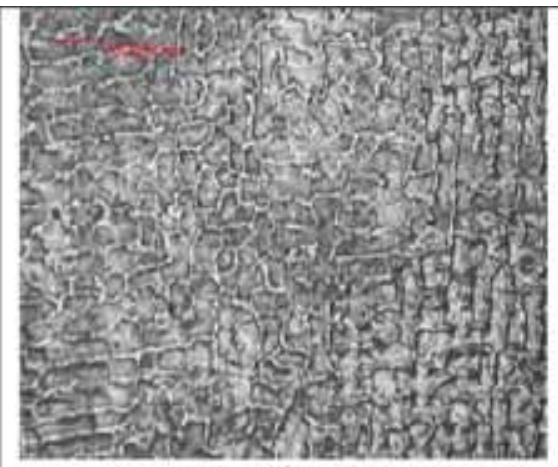

2. Magnification (X100)

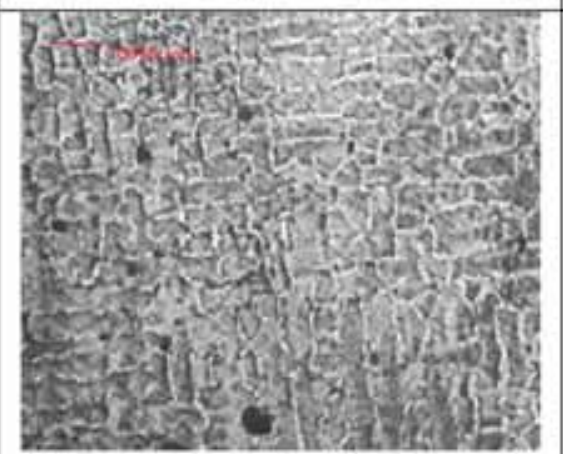

4. Magnification (X100)

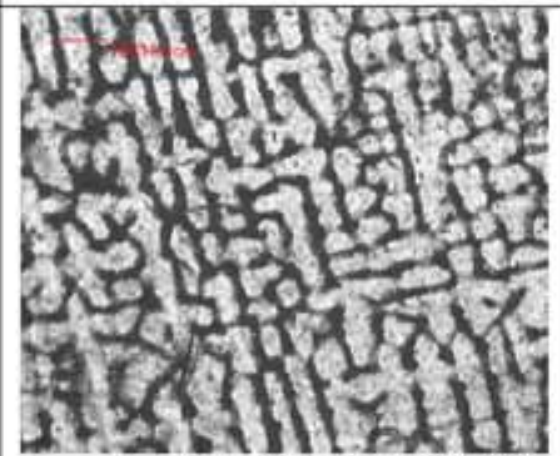

5. Magnification $(\mathrm{X} 100)$

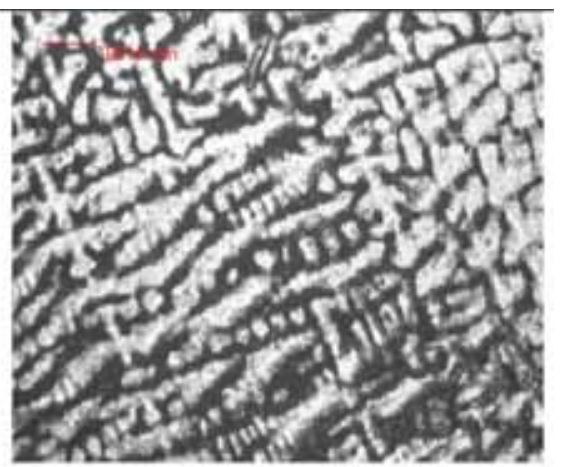

3. Magnification (X100)

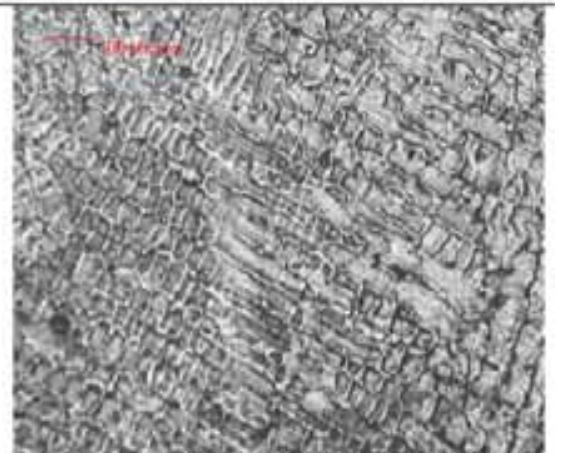

6. Magnification (X100)

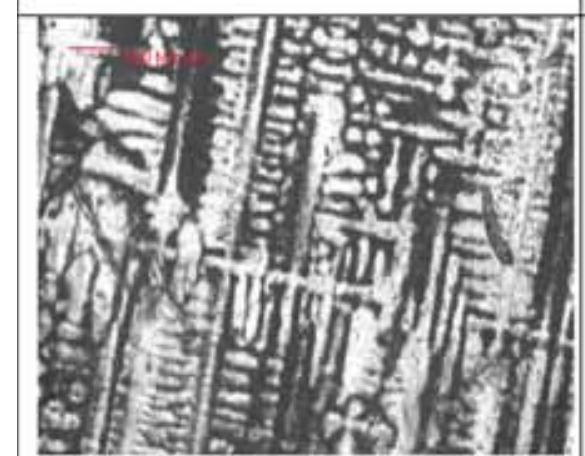

7. Magnification $(\mathrm{X} 100)$

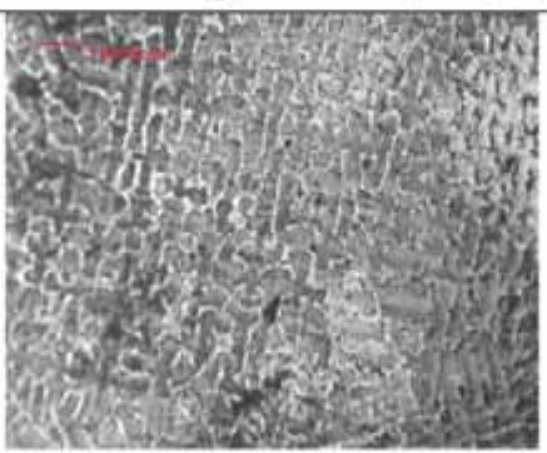

8. Magnification (X100)

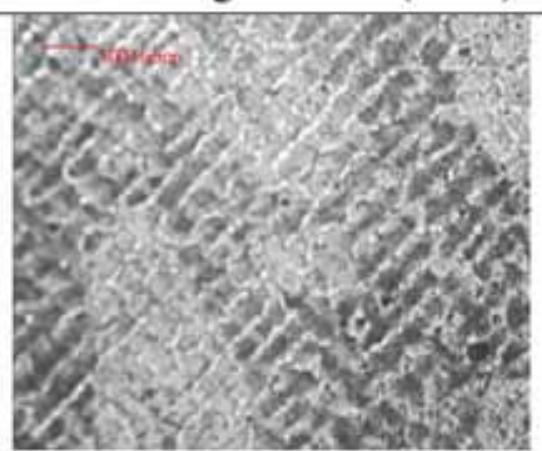

9. Magnification (X100)

Figure 6. Photomicrographs of final nine castings on magnification $(\times 100)$.

$$
\begin{gathered}
X=(1 / n) \sum Y^{2} \\
2.93263 \times 10^{-6}=Y^{2}(\text { here } n=1) \\
Y^{2}=2.93263 \times 10^{-6} \\
Y=0.001712492(\text { minimum value of } \Delta d)
\end{gathered}
$$

where $Y$ is the value of the property.

Similarly, for SN ratio of $R_{\mathrm{a}}$, final minimum value of the property has been predicted with the help of the following relations. 3.1b Regression equation for $S N$ ratio of $R_{a}$ :

$$
\begin{aligned}
\text { SNRA2 }= & -16.02-(0.56 \times-16.58)+(2.92 \times-13.10) \\
& -(2.37 \times-18.39)-(1.72 \times-17.74)+(1.77 \times-14.25) \\
& -(0.05 \times-16.07)-(1.08 \times-17.10) \\
& +(0.99 \times-15.03)+(0.09 \times-15.93)
\end{aligned}
$$

SNRA2 $=6.8455$.

Rewriting Eq. (2) and putting values in it from table 4 
Table 10. Grain size and porosity of 9 experiments.

\begin{tabular}{lccc}
\hline $\begin{array}{l}\text { Exp. } \\
\text { no. }\end{array}$ & $\begin{array}{c}\text { Grain size no. } \\
G\end{array}$ & $\begin{array}{c}\text { Grain size diameter } \\
(\mu \mathrm{m})\end{array}$ & $\begin{array}{c}\text { Porosity } \\
(\%)\end{array}$ \\
\hline 1 & 5.75 & $44.90-53.40$ & 50.11 \\
2 & 5.75 & $44.90-53.40$ & 51.00 \\
3 & 4.50 & 75.50 & 64.60 \\
4 & 5.00 & 63.50 & 30.05 \\
5 & 4.75 & $63.50-75.50$ & 57.81 \\
6 & 6.25 & $37.80-44.90$ & 40.20 \\
7 & 4.75 & $63.50-75.50$ & 66.52 \\
8 & 4.25 & $75.50-89.90$ & 45.38 \\
9 & 4.25 & $75.50-89.90$ & 41.07 \\
\hline
\end{tabular}

$\mathrm{SN}$ ratio $=-10 \log X$

(standard equation for finding $\mathrm{SN}$ ratio)

$$
\begin{aligned}
& 6.8455=-10 \log X \\
& X=10^{-0.68455} \\
& X=0.206752134
\end{aligned}
$$

Now put value of $X$ in the next equation:

$$
\begin{gathered}
X=(1 / n) \sum Y^{2} \\
0.206752134=Y^{2}(\text { here } n=1) \\
Y^{2}=0.206752134 \\
Y=0.454700048\left(\text { minimum value of } R_{a}\right) .
\end{gathered}
$$

\section{1c Regression equation for $S N$ ratio of $H V$ :}

$$
\begin{gathered}
\text { SNRA3 }=44.7041-(0.2718 \times 44.43)+(0.4166 \times 45.12) \\
-(0.1448 \times 44.56)-(0.2220 \times 44.48) \\
-(0.1386 \times 44.57)+(0.3606 \times 45.06) \\
+(0.4016 \times 45.11)+(0.3324 \times 45.04) \\
-(0.7341 \times 43.97), \\
\text { SNRA3 }=45.978499 .
\end{gathered}
$$

Rewriting Eq. (2) and putting values in it from table 4

$\mathrm{SN}$ ratio $=-10 \log X$ (standard equation for finding $\mathrm{SN}$ ratio)

$$
\begin{aligned}
& 45.978499=-10 \log X \\
& X=10^{-4.5978499} \\
& X=2.52435 \times 10^{-5} .
\end{aligned}
$$

Now put value of $X$ in the next equation:

$$
\begin{gathered}
X=(1 / n) \sum 1 / Y^{2} \\
2.52435 \times 10^{-5}=1 / Y^{2}(\text { here } n=1) \\
Y^{2}=1 / 2.52435 \times 10^{-5} \\
Y=199.0329362
\end{gathered}
$$$$
\text { (maximized value of } \mathrm{HV} \text { ). }
$$

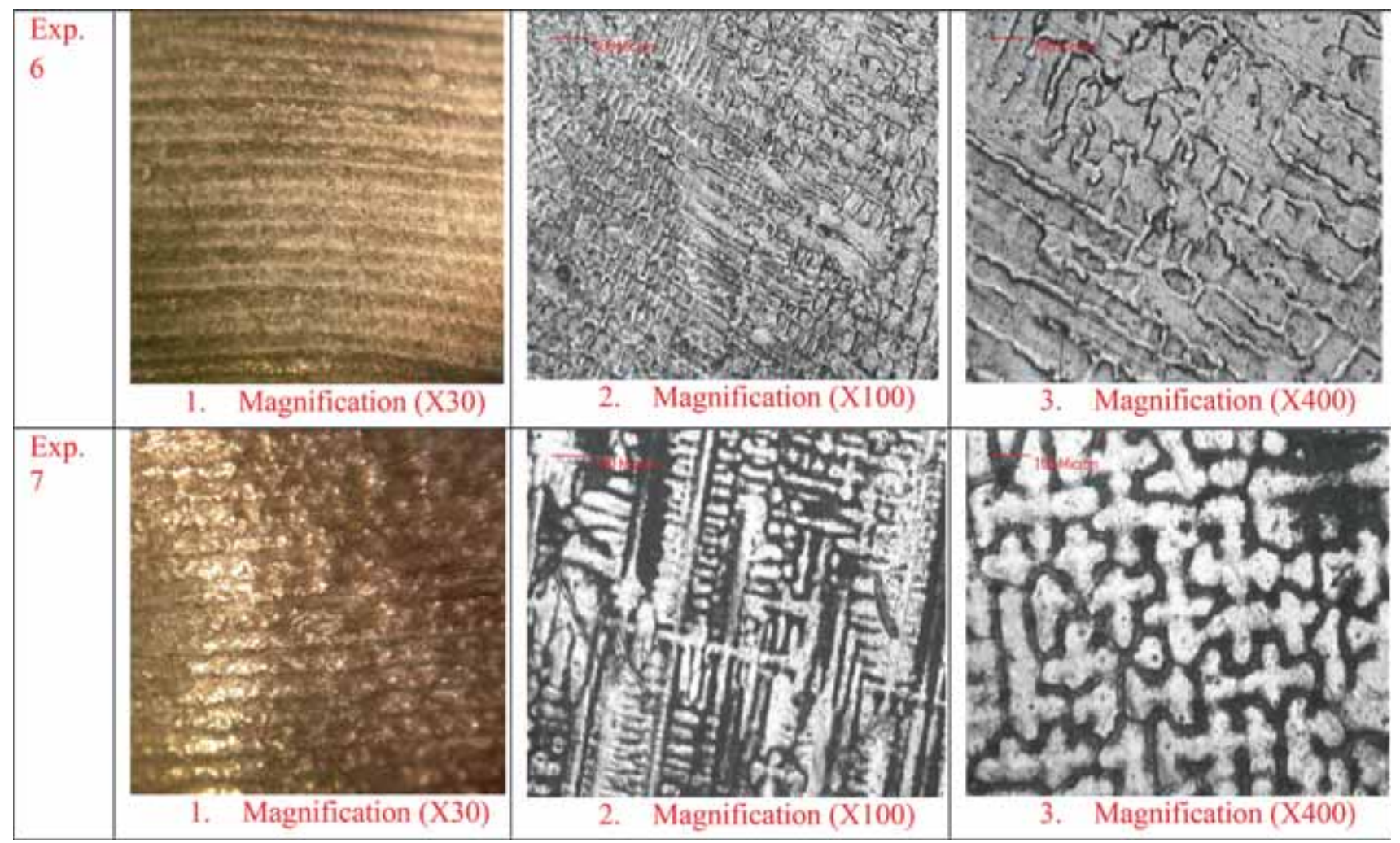

Figure 7. Photomicrographs of experiments 6 and 7. 


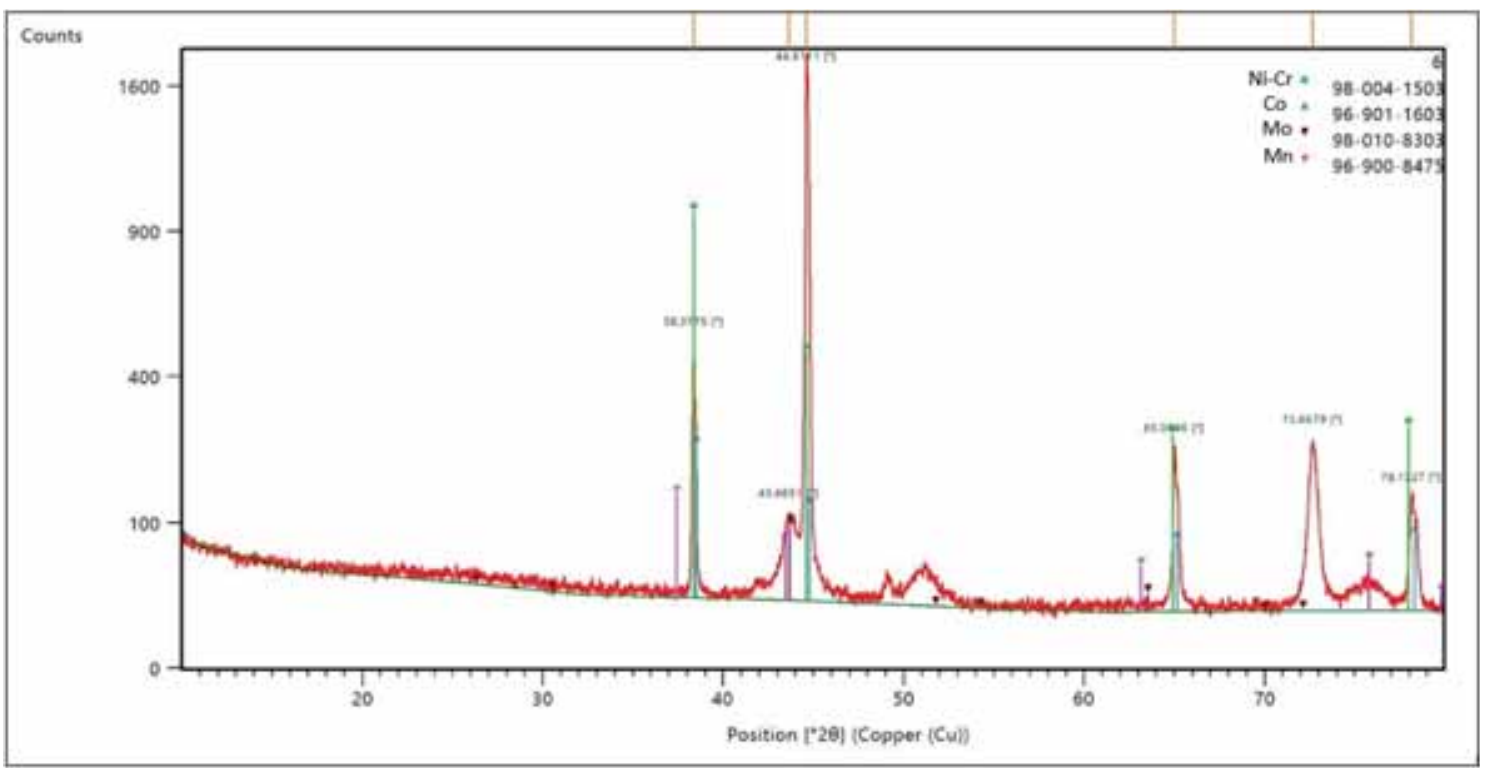

Figure 8. XRD graph for exp. no. 6 .

The predicted value of $S / N$ ratios that comes out after solving the model equation has values very near to the obtained/deduced values in table 3. Hence, this verifies the validity of the macro-model. Figure 5 shows the optimization plot after regression analysis based on outputs of $\mathrm{SN}$ ratios.

In order to ascertain the metallurgical properties, photomicrographs were taken [40] for all sets of experiments as per table 3 using a metallurgical microscope at $\times 100$ magnifications. Figure 6 shows the photomicrographs for all nine samples as per table 3 .

The grain size and porosity were also examined on greyscale. Table 10 shows the grain size no. $G$ against grain size diameter as per ASTM E1382 and porosity (\%) as per ASTM B276.

As observed from table 10, experiment no. 4 has minimum porosity followed by experiment no. 6 . Further, actual average grain size diameter for experiment no. 6 is the smallest; also the hardness observed is maximum (see table 3). This may be because of combined effect of porosity level and average grain size.

To correlate hardness with dendrite structure, comparison of samples 6 and 7 has been made (see figure 7). As observed from figure 7 at low magnification $(\times 30)$, surface texture is observed to have more waviness, whereas at high magnification $(\times 400)$ dendrite size and spacing observed are of large dimensions. The average grain size diameter for experiment number 6 was $\Phi 37.8-44.9 \mu \mathrm{m}$ and for experiment number 7 it was $\Phi 63.50-75.50 \mu \mathrm{m}$; corresponding porosity for experiment number 6 was $40.2 \%$ and for experiment number 7 it was $66.52 \%$. Hence, average grain size of partial denture cast in experiment no. 6 is relatively fine with less $\%$ of porosity in comparison with cast prepared in experiment no. 7 with high $\%$ of porosity. Hence, the partial denture cast with coarse grains in experimental no. 7 resulted in less hardness as compared with partial denture cast with fine grain structure in experiment no. 6. These results are in line with the observations made by other investigators [18, 31, 32, 40-42].

In order to ascertain the chemical composition of cast components, figure 8 shows the XRD graph with $61 \%$ of $N$ (for sample no. 6 as per table 3), which confirms the presence of alloying elements in final functional prototype as per table 2 .

\section{Conclusions}

This study highlights the multifactor optimization for mechanical properties of $\mathrm{Ni}-\mathrm{Cr}$-based partial dentures prepared by AM assisted with CC. The regression equations have been deduced for predicting the $S / N$ ratios and output parameters.

The results of study suggest that for controlling the dimensional features and surface roughness of the partial dentures, the most important factor is ' $W$ ' followed by ' $N$ ' in $\mathrm{Ni}-\mathrm{Cr}$ alloy.

For hardness of partial dentures, the most important factor is ' $N$ '.

The proposed optimized settings resulted in more uniform grain size of $\Phi 37.8-44.9 \mu \mathrm{m}$ and controlled porosity level of $40.2 \%$ acceptable in clinical dentistry.

Finally, from overall multifactor optimization viewpoint for field applications the best settings are $W$-100/15, $H$-pH7 and $\mathrm{N}-61 \% \mathrm{Ni}$ proportion in $\mathrm{Ni}-\mathrm{Cr}$ alloy. 


\section{Acknowledgements}

The authors would like to thank Manufacturing Research Lab (Production Engineering, GNDEC Ludhiana) for all the help to carry out this research work.

\section{References}

[1] Eggbeer D, Bibb R and Williams R 2005 The computeraided design and rapid prototyping fabrication of removable partial denture frameworks. J. Eng. Med. 219(3): 195-202

[2] Bibb R, Eggbeer D and Williams R 2006 Rapid manufacture of removable partial denture frameworks. Rapid Prototyp. J. 12(2): 95-99

[3] Dawood A, Marti B M, Sauret-Jackson V and Darwood A 2015 3D printing in dentistry. Br. Dent. J. 219: 521

[4] Heydecke G, Vogeler M, Wolkewitz M, Türp J C and Strub J R 2008 Simplified versus comprehensive fabrication of complete dentures: patient ratings of denture satisfaction from a randomized crossover trial. Quintessence Int. 39(2): $107-116$

[5] Chang C C, Lee M Y and Wang S H 2006 Digital denture manufacturing - an integrated technologies of abrasive computer tomography, CNC machining and rapid prototyping. Int. J. Adv. Manuf. Technol. 31(1): 41-49

[6] Lee M Y, Chang C C and Ku Y C 2008 New layer-based imaging and rapid prototyping techniques for computeraided design and manufacture of custom dental restoration. $J$. Med. Eng. Technol. 32(1): 83-90

[7] Lee M Y and Chang C C 2010 Layer-based abrasive computer tomography for custom denture fabrication. In: Proceedings of the IEEE International Conference on System Science and Engineering (ICSSE), IEEE, pp. 577-582

[8] Seferli J, Michelin M, Klinge B and Wettergren L 2014 Patients experiences of dental implant placement for treatment of partial edentulism in a student clinic setting. Swed. Dent. J. 38(2): 77-85

[9] Kattadiyil M T, Parciak E, Puri S and Scherer M D 2014 CAD/CAM guided surgery in implant dentistry: a brief review. Alpha Omegan 107(1): 26-31

[10] Anderson P J, Yong R, Surman T L, Rajion Z A and Ranjitkar S 2014 Application of three-dimensional computed tomography in craniofacial clinical practice and research. Aust. Dent. J. 59: 174-185

[11] Sokovic M and Kopac J 2006 RE (reverse engineering) as necessary phase by rapid product development. J. Mater. Process. Technol. 175(1-3): 398-403

[12] Bagci E 2009 Reverse engineering applications for recovery of broken or worn parts and re-manufacturing: three case studies. Adv. Eng. Softw. 40(6): 407-418

[13] Bi Z M and Wang L 2010 Advances in 3D data acquisition and processing for industrial applications. Robot. Comput. Integr. Manuf. 26(5): 403-413

[14] Geng Z and Bidanda B 2017 Review of reverse engineering systems-current state of the art. Virtual Phys. Prototyp. 12(2): 161-172

[15] Liaw C Y and Guvendiren M 2017 Current and emerging applications of 3D printing in medicine. Biofabrication $9(2)$ : 024102
[16] Farjood E, Vojdani M, Torabi K and Khaledi A A R 2017 Marginal and internal fit of metal copings fabricated with rapid prototyping and conventional waxing. J. Prosthet. Dent. 117(1): 164-170

[17] Litjens G, Kooi T, Bejnordi B E, Setio A A A, Ciompi F, Ghafoorian M, Van Der Laak J A, Van Ginneken B and Sánchez C I 2017 A survey on deep learning in medical image analysis. Med. Image Anal. 42: 60-88

[18] Singh G, Singh R and Singh S 2018 Nickel chromium based partial denture preparation: conventional vs additive manufacturing techniques. Ref. Module Mater. Sci. Mater. Eng. https://doi.org/10.1016/b978-0-12-803581-8.11243-3

[19] Milewski J O 2017 Additive manufacturing of metals: from fundamental technology to rocket nozzles, medical implants, and custom jewelry. Springer Ser. Mater. Sci. 258: 310-323

[20] Quadri S, Kapoor B, Singh G and Tewari R K 2017 Rapid prototyping: an innovative technique in dentistry. J. Oral Res. Rev. 9(2): 96-102

[21] Azari A and Nikzad S 2009 The evolution of rapid prototyping in dentistry: a review. Rapid Prototyp. J. 15(3): 216-225

[22] Torabi K, Farjood E and Hamedani S 2015 Rapid prototyping technologies and their applications in prosthodontics, a review of literature. J. Dent. 16(1): 1-6

[23] Yan G D, Liao W H, Dai N, Yang L, Gao Y G, Zhu S Y and Cai Y H 2009 The computer-aided design and rapid prototyping fabrication of removable partial denture framework. In: Proceedings of the $2^{\text {nd }}$ IEEE International conference on Computer Science and Information Technology, IEEE, pp. 266-268

[24] Masood S H 1996 Intelligent rapid prototyping with fused deposition modelling. Rapid Prototyp. J. 2(1): 24-33

[25] Bilgin M S, Baytaroğlu E N, Erdem A and Dilber E 2016 A review of computer-aided design/computer-aided manufacture techniques for removable denture fabrication. Eur. J. Dent. 10(2): 286-290

[26] Alharbi N, Osman R and Wismeijer D 2016 Effects of build direction on the mechanical properties of 3D-printed complete coverage interim dental restorations. J. Prosthet. Dent. 115(6): 760-767

[27] Chohan J S and Singh R 2017 Pre and post processing techniques to improve surface characteristics of FDM parts: a state of art review and future applications. Rapid Prototyp. $J$. 23(3): 495-513

[28] Gausemeier J, Echterhoff N, Kokoschka M and Wall M 2012 Thinking ahead the future of additive manufacturing - future applications. In: Proceedings of the Study for the Direct Manufacturing Research Center, Paderborn, pp. 34-52

[29] Jayaprakash K, Upadhya P N, Nandish B T, Shetty A N, Shetty K H K, Ginjupalli K, Voddya S B and Prabhu S 2014 Impact of water quality and water powder ratio on the properties of type 4-die stones (gypsum products) used in dentistry. Int. J. Health Rehabil. Sci. 3: 75-81

[30] McCabe J F and Walls AW 2013 Applied Dental Materials. Wiley, New York

[31] Singh R, Singh S and Singh G 2014 Dimensional accuracy comparison of investment castings prepared with wax and ABS patterns for bio-medical application. Procedia Mater. Sci. 6: 851-858

[32] Singh R and Singh G 2015 Cast component hardness comparison for investment casting prepared with wax and ABS patterns. Trans. Indian Inst. Met. 68(1): 17-21 
[33] Tandon K, Singh A and Chandra S 2014 A comparative evaluation of conventional vs accelerated casting technique, as regards marginal fit and surface roughness. IOSR J. Dent. Med. Sci. 13(10): 06-10

[34] Roberts H W, Berzins D W, Moore B K and Charlton D G 2009 Metal ceramic alloys in dentistry: a review. J. Prosthodont. Implant Esthet. Reconstr. Dent. 18(2): 188-194

[35] Kim E H, Lee D H, Kwon S M and Kwon T 2017 A microcomputed tomography evaluation of the marginal fit of cobalt-chromium alloy copings fabricated by new manufacturing techniques and alloy systems. J. Prosthet. Dent. 117(3): 393-399

[36] Jei J B and Mohan J 2014 Comparative evaluation of marginal accuracy of a cast fixed partial denture compared to soldered fixed partial denture made of two different base metal alloys and casting techniques: an in vitro study. $J$. Indian Prosthodont. Soc. 14(1): 104-109

[37] Wu J C, Lai L C, Sheets C G, Earthman J and Newcomb R 2011 A comparison of the marginal adaptation of cathode-arc vapor-deposited titanium and cast base metal copings. $J$. Prosthet. Dent. 105(6): 403-409
[38] Da Silva L J, Leal M B, Valente M L, De Castro D T, Pagnano V O, Dos Reis A C and Bezzon O L 2017 Effect of casting atmosphere on the marginal deficiency and misfit of Ni-Cr alloys with and without beryllium. J. Prosthet. Dent. 118(1): 83-88

[39] Cogolludo P G, Suárez M J, Peláez J and Lozano J F 2010 Influence of melting and casting methods and finish line design on the marginal discrepancy of nickel-chromiumtitanium alloy crowns. Int. J. Prosthodont. 23(5): 443-445

[40] Singh R and Ranjan N 2018 Experimental investigations for preparation of biocompatible feedstock filament of fused deposition modeling (FDM) using twin screw extrusion process. J. Thermoplast. Compos. Mater. 31(11): 1455-1469

[41] Singh R and Singh G 2017 Investigations for modelling hardness of biomedical implant during replication of FDM based patterns by vacuum moulding. Sadhana 42(3): 327-333

[42] Singh J, Singh R, Singh H and Verma A K 2018 Investigations for mechanical properties and biocompatibility of SS316L implant prepared as rapid investment casting for batch production. Sadhana 43: 1-10 